\title{
Integrin $\beta 1$-mediated acquired gefitinib resistance in non-small cell lung cancer cells occurs via the phosphoinositide 3-kinase-dependent pathway
}

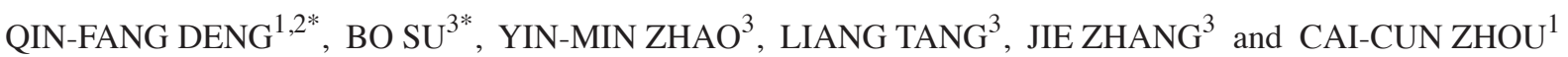 \\ ${ }^{1}$ Department of Oncology, Shanghai Pulmonary Hospital, Tongji University School of Medicine, Shanghai 200433; \\ ${ }^{2}$ Department of Oncology, School of Medicine, Soochow University, Suzhou 215007; ${ }^{3}$ Central Laboratory, \\ Shanghai Pulmonary Hospital, Tongji University, Shanghai 200433, P.R. China
}

Received November 10, 2014; Accepted September 24, 2015

DOI: $10.3892 / \mathrm{ol} .2015 .3945$

\begin{abstract}
The present study aimed to explore the role of integrin $\beta 1$ and the relevant signaling pathways in acquired gefitinib resistance in non-small cell lung cancer (NSCLC). The inhibitory effects of gefitinib, with or without LY294002, on cellular proliferation were evaluated by 3-(4,5-dimethylthiazol-2-yl) 2,5-diphenyltetrazolium bromide assay. Cell cycle progression and apoptosis were analyzed by flow cytometry, while western blotting was used to evaluate the expression of EGFR, phosphorylated (phospho)-EGFR, protein kinase B (Akt), phospho-Akt, extracellular signal-regulated kinase (Erk) and phospho-Erk. The gene expression profiles of PC9 and PC9/G cells were determined by DNA microarray. Integrin $\beta 1$ was knocked down in PC9/G cells by transiently transfected short interfering RNA (siRNA). A scrambled siRNA sequence was used as a control. Apoptosis of transfected cells was determined by Annexin V-phycoerythrin-Cy5/propidium iodide staining. Sequencing products were amplified by nested PCR. The resistant index of PC9/G cells to gefitinib was $\sim 138$ - to 256-fold higher than that of PC9 cells, and this resistance was accompanied by significant increase in integrin $\beta 1$ expression in PC9/G cells. Knockdown of integrin $\beta 1$ with short hairpin RNA in PC9/G cells markedly inhibited proliferation and enhanced apoptosis in response to gefitinib, restoring the sensitivity of PC9/G cells gefitinib. Phosphoinositide 3-kinase (PI3K)/Akt activation was observed in PC9/G cells in the presence of gefitinib and the sensitivity of PC $9 / \mathrm{G}$ cells to gefitinib was also able to be restored by PI3K/Akt pathway inhibitor
\end{abstract}

Correspondence to: Dr Cai-Cun Zhou, Department of Oncology, Shanghai Pulmonary Hospital, Tongji University School of Medicine, 507 Zhengmin Road, Shanghai 200433, P.R. China

E-mail: caicunzhou@yahoo.com.cn

*Contributed equally

Key words: drug resistance, epidermal growth factor receptor inhibition, tyrosine kinase inhibitor, integrin
LY294002. Finally, knockdown of integrin $\beta 1$ significantly reduced the levels of phospho-Akt. These findings suggest that integrin $\beta 1$ signaling via the PI3K/Akt pathway may be a significant mechanism underlying gefitinib resistance, and may potentially present an alternative therapeutic target for the treatment of NSCLC unresponsive to EGFR inhibitors.

\section{Introduction}

Molecular targeted therapies have become the most promising potential treatment for lung cancer, the leading cause of cancer-associated mortality worldwide (1). As a generally accepted treatment target, epidermal growth factor receptor (EGFR) is involved in numerous carcinogenic processes, including cell invasion, proliferation, apoptosis and angiogenesis (2). Two small molecule inhibitors of EGFR (erlotinib and gefitinib) have been used extensively in clinical settings and have demonstrated marked effects in the treatment of patients with non-small cell lung cancer (NSCLC) with activating EGFR mutations $(3,4)$. However, a number of patients do not benefit from such inhibitors, and even those who initially exhibit a positive response to EGFR inhibitors may eventually become refractory (5). It has been reported that the remission rate of gefitinib and erlontinib used in the secondor third-line of NSCLC treatment is $9-27 \%$, and among these cases 50\% relapse 6-12 months later (5). To further improve the efficacy of EGFR tyrosine kinase inhibitors (TKIs), a greater understanding of the mechanisms underlying such resistance is required.

To date, the mechanisms underlying resistance to EGFR TKIs have mainly focused on several aspects: Secondary mutation of the EGFR gene exon 20 (6), the constitutive activation of downstream signaling pathways, epithelial-mesenchymal transition (EMT) associated with intrinsic and acquired resistance (7,8), c-MET gene amplification (9), increased angiogenesis and tumor micro-circumstance associated drug resistance $(7,10)$. Recently, cell adhesion-mediated drug resistance (CAM-DR) has attracted increasing attention. Changes in the tumor microenvironment, including adhesion molecules and their receptors, cytokines and the extracellular matrix (ECM), for example fibronectin and collagen I, may 
A

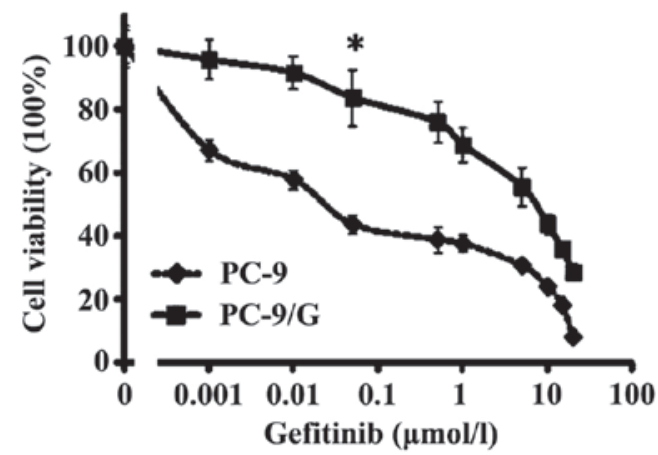

C

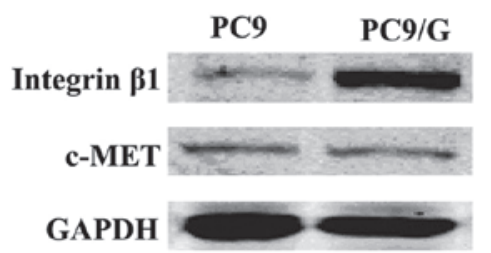

B

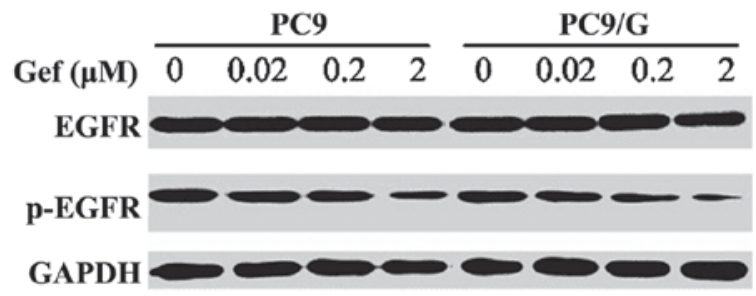

D

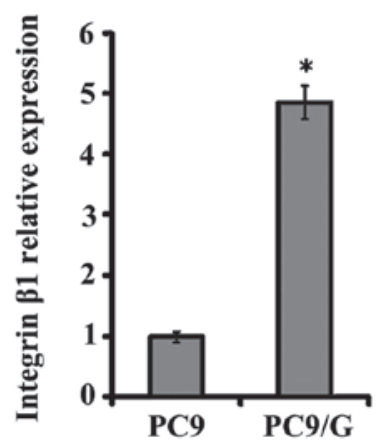

Figure 1. Characterization of the PC9/G gefitinib-resistant cell line. (A) Growth-inhibitory effect of Gef on PC9 and PC9/G cells determined by MTT assay. Cells were seeded on 96-well plates in quadruplicate, and cultured in the indicated concentrations of Gef. Following $72 \mathrm{~h}$ of incubation, the cells were subjected to MTT assay. "P $<0.05$ vs. PC9 cells. (B) Western blot analysis of EGFR and p-EGFR in PC9 and PC9/G cells. Cells were placed in medium containing 0 , $0.02,0.2$ and $2 \mu \mathrm{M}$ of gefitinib for $6 \mathrm{~h}$. Samples were separated by SDS-PAGE with a $20 \mu \mathrm{g}$ sample of cell lysate loaded into each well. No marked difference in p-EGFR inhibition was identified between PC9 and PC9/G cells. (C) Western blot analysis of integrin $\beta 1$ and c-MET expression in PC9 and PC9/G cells. A $20 \mu \mathrm{g}$ sample of cell lysate was separated by SDS-PAGE, transferred to membranes and incubated with the indicated antibodies as the first antibody and then with horseradish peroxidase-conjugated secondary antibody. (D) Polymerase chain reaction analysis of integrin $\beta 1$ messenger RNA level in PC9 and PC9/G cells. "P<0.05 vs. PC9 cells. Gef, gefitinib; MTT, 3-(4,5-dimethylthiazol-2-yl)-2,5-diphenyltetrazolium bromide; EGFR, epidermal growth factor receptor; p, phosphorylated; SDS-PAGE, sodium dodecyl sulfate polyacrylamide gel electrophoresis.

induce resistance of NSCLC to EGFR TKIs (10). Integrin is one of the most significant adhesion molecules that has been suggested to be involved in CAM-DR (11). Integrins are transmembrane heterodimers that consist of non-covalently bound $\alpha$ and $\beta$ glycoprotein subunits and transmit biomechanical cues to mediate cell-ECM interactions $(12,13)$. The loss of integrin-mediated anchorage to the ECM may result in cell apoptosis, known as anoikis, in epithelial or endothelial cells, indicating a significant role for this molecule in the control of tumorigenesis. It has also been reported that integrins mediating cell-ECM signaling are able to affect various tumor cell behaviors, including proliferation, survival, invasion and metastasis $(14,15)$. Increasing evidence has suggested that the integrin $\beta 1$ signaling pathway has a significant role in mediating resistance to chemotherapies by enhancing cell survival in myeloma, glioblastoma, ovarian cancer and lung cancer (16-19). Given that integrins and EGFR share a number of downstream signaling pathways, including protein kinase B (Akt) (20), it was hypothesized that integrin may be involved in inducing the resistance of NSCLC to EGFR TKIs.

In the present study, a gefitinib-resistant $\mathrm{PC} 9 / \mathrm{G}$ cell line was generated by exposure of PC9 cells to mutagen, $\mathrm{N}$-methyl- $N$ '-nitro- $N$-nitrosoguanidine (MNNG), with gefitinib, and it was found that expression of integrin $\beta 1$ was higher in PC9/G cells than that in the parental cell line, PC9. Knockdown of integrin $\beta 1$ by RNA interference (RNAi) was able to restore the sensitivity of PC $9 / \mathrm{G}$ cells to gefitinib. Furthermore, it was demonstrated that such a restoration may be induced via inactivation of the phosphoinositide 3-kinase (PI3K) pathway. These results therefore reveal a potential mechanism by which NSCLC may acquire resistance to EGFR antagonists.

\section{Materials and methods}

Reagents. Gefitinib was purchased from AstraZeneca (Macclesfield, UK). The PI3K inhibitor, LY294002, was purchased from Sigma-Aldrich (St. Louis, MO, USA). Monoclonal human anti-mouse integrin $\beta 1$ antibody $\left(1: 1,000\right.$; cat. no. CBL481P) was obtained from Chemicon ${ }^{\circledR}$ (Merck Millipore, Darmstadt, Germany). Monoclonal human anti-rabbit c-MET (1:1,000; cat. no. 8198), polyclonal human anti-rabbit Akt (1:1,000; cat. no. 9272), polyclonal human anti-rabbit phosphorylated (phospho)-Akt (Ser473; 1:1,000; cat. no. 9271), polyclonal human anti-rabbit Erk (1:1,000; cat. no. 4695), monoclonal human anti-rabbit phospho-Erk (1:1,000; cat. no. 4370), polyclonal human anti-rabbit EGFR (1:1,000; cat. no. 2232) and polyclonal human anti-rabbit phospho-EGFR (1:1,000; cat. no. 2234) antibodies were purchased from Cell Signaling Technology, Inc. (Danvers, MA, USA). Monoclonal rabbit anti-mouse GAPDH antibody (1:10,000; cat. no. KC-5G5) was purchased from Shanghai Kangchen Bio-technology Co. (Shanghai, China). Gibco 
Table I. Effect of gefitinib with or without LY294002 on cell proliferation, apoptosis and cell cycle progression of PC9/G cells.

A, Gefitinib alone

\begin{tabular}{lcccc}
\hline & & & \multicolumn{2}{c}{ Cell cycle phase, $\%$} \\
\cline { 3 - 5 } Cell & $\mathrm{IC}_{50}$ values, $\mu \mathrm{M}$ & Apoptotic rate, $\%$ & $\mathrm{G} / \mathrm{G} 1$ & $\mathrm{~S}$ \\
\hline PC9 & $0.06 \pm 0.008$ & $26.2 \pm 4.55$ & $72.6 \pm 5.39$ & $6.8 \pm 1.6$ \\
PC9/G & $7.29 \pm 0.39$ & $6.7 \pm 0.36$ & $62.2 \pm 3.3$ & $15.8 \pm 2.8$ \\
\hline
\end{tabular}

\section{B, Gefitinib+LY294002}

\begin{tabular}{|c|c|c|c|c|}
\hline \multirow[b]{2}{*}{ Cell } & \multirow[b]{2}{*}{$\mathrm{IC}_{50}$ values, $\mu \mathrm{M}$} & \multirow[b]{2}{*}{ Apoptotic rate, $\%$} & \multicolumn{2}{|c|}{ Cell cycle phase, $\%$} \\
\hline & & & $\mathrm{G} 0 / \mathrm{G} 1$ & $\mathrm{~S}$ \\
\hline PC9 & $0.05 \pm 0.009$ & $24.8 \pm 2.38$ & $75.1 \pm 4.3$ & $4.5 \pm 1.5$ \\
\hline $\mathrm{PC} 9 / \mathrm{G}$ & $0.092 \pm 0.005^{\mathrm{a}}$ & $21.0 \pm 0.81^{\mathrm{a}}$ & $76.7 \pm 4.6^{\mathrm{a}}$ & $8.9 \pm 3.8^{\mathrm{a}}$ \\
\hline
\end{tabular}

For apoptosis and cell cycle analysis, PC9 and PC9/G cells were treated with $0.1 \mu \mathrm{mol} / 1$ gefitinib with or without $25 \mu \mathrm{mol} / 1 \mathrm{LY} 294002 \mathrm{for} 72 \mathrm{~h}$. Student's t-test, ${ }^{\mathrm{a}} \mathrm{P}<0.05$ vs. gefitinib treatment alone. Values are expressed as the mean \pm standard deviation of three independent experiments. ITGB1, integrin $\beta 1$; si, short interfering.

Table II. Effect of gefitinib on cell cycle distribution of PC9 and PC $9 / \mathrm{G}$ cells.

A, Cell cycle analysis prior to gefitinib treatment

\begin{tabular}{lccc}
\hline & \multicolumn{3}{c}{ Cell cycle phase, \% } \\
\cline { 2 - 4 } Cell type & $\mathrm{G} 0 / \mathrm{G} 1$ & $\mathrm{~S}$ & $\mathrm{G} 2 / \mathrm{M}$ \\
\hline PC9 & $49.2 \pm 4.1^{\mathrm{a}}$ & $28.3 \pm 1.5$ & $22.6 \pm 2.0$ \\
PC9/G & $53.8 \pm 4.5$ & $23.0 \pm 1.2$ & $23.2 \pm 1.9$ \\
\hline
\end{tabular}

$\mathrm{B}$, Cell cycle analysis following gefitinib treatment

\begin{tabular}{lccc}
\hline & \multicolumn{3}{c}{ Cell cycle phase, \% } \\
\cline { 2 - 4 } Cell type & $\mathrm{G} 0 / \mathrm{G} 1$ & $\mathrm{~S}$ & $\mathrm{G} 2 / \mathrm{M}$ \\
\hline PC9 & $87.6 \pm 4.3^{\mathrm{a}, \mathrm{b}}$ & $2.3 \pm 0.6$ & $7.5 \pm 0.8$ \\
PC9/G & $60.9 \pm 3.5^{\mathrm{b}}$ & $17.9 \pm 1.3$ & $21.2 \pm 2.1$
\end{tabular}

PC9 and PC9/G cells were treated with $0.03 \mu \mathrm{mol} / 1$ gefitinib for $24 \mathrm{~h}$. Student's t-test, ${ }^{\mathrm{a}} \mathrm{P}<0.05$, PC9 cells alone vs. PC9 cells following gefitinib treatment; ${ }^{\mathrm{b}} \mathrm{P}<0.05$, $\mathrm{PC} 9$ cells following gefitinib treatment vs. PC9/G cells following gefitinib treatment. Values are expressed as the mean \pm standard deviation of three independent experiments.

Dulbecco's modified Eagle's medium was from Thermo Fisher Scientific, Inc. (Waltham, MA, USA).

Cell culture and transfection. The PC9 human lung adenocarcinoma cell line (passage number, 10; negative for mycoplasmic infection) was provided by Dr Takayama (Kyushu University, Fukuoka, Japan). A gefitinib-resistant PC9/G cell line was established according to the protocol reported by Koizumi et al (21). Briefly, cultured PC9 cells were exposed to $2.5 \mu \mathrm{g} / \mathrm{ml}$ MNNG (Sinopharm Chemical Reagent Co., Ltd., Shanghai, China) for $24 \mathrm{~h}$, washed and cultured in medium supplemented with $0.2 \mu \mathrm{M}$ gefitinib for 7 days. Following exposure to gefitinib, cells were washed and cultured in drug-free medium (Gibco; Thermo Fisher Scientific, Inc.) for 14 days. When the number of variable cells had increased to $90 \%$, as determined by trypan blue (Sigma-Aldrich) exclusion, cells $\left(3 \times 10^{3} / \mathrm{ml}\right)$ were seeded on 96 -well culture plates in medium containing $0.3-0.5 \mu \mathrm{M}$ gefitinib for subcloning. Following 21 days of culture, colonies were harvested by trypsinization and a single clone was obtained. The cell line was maintained in medium containing $0.05 \mu \mathrm{mol} / 1$ gefitinib at $37^{\circ} \mathrm{C}$ in a humidifed atmosphere of $5 \% \mathrm{CO}_{2}$.

Integrin $\beta 1$ short hairpin RNA (shRNA)-pRNAT-U6.1/Neo vectors were generated by Shanghai Kangchen Bio-technology Co. To construct integrin $\beta 1$ shRNA, sense and antisense DNA oligonucleotides were designed from double-stranded RNA with a loop structure: Integrin $\beta 1$ shRNA [short interfering (si)-ITGB1] sense, 5'-GGATTCTGACAGCTTTAAA-3' and antisense, 5'-TTTAAAGCTGTCAGAATCC-3'. A scrambled sequence (si-scrambled; 5'-TTCTCCGAACGTGTACGT-3'; Shanghai Kangchen Bio-technology Co.) was used as a control. Cells were transfected with Lipofectamine ${ }^{\circledR} 2000$ reagent (Invitrogen; Thermo Fisher Scientific) according to the manufacturer's protocol. The transient transfection efficiency for PC9 and PC9/G cells was $65-75 \%$, as determined by green fluorescent protein plasmid transfection. Briefly, PC9 and PC9/G cells were grown to $80 \%$ confluence on six-well plates, washed twice with serum free medium (Gibco; Thermo Fisher Scientific, Inc.), resuspended in antibiotic-free DMEM ( $5 \times 10^{5}$ cells $/ \mathrm{ml}$; Gibco; Thermo Fisher Scientific, Inc.) and transfected with $16 \mu \mathrm{g} / \mathrm{ml}$ total DNA using Lipofectamine 2000 (1:5 ratio). After $6 \mathrm{~h}$, the transfection medium was removed 
A

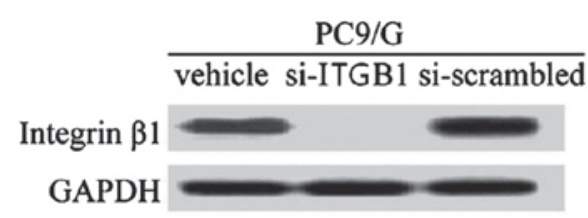

C

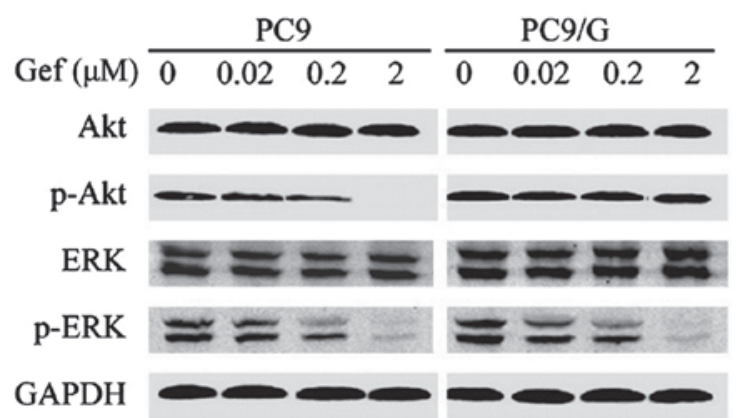

B

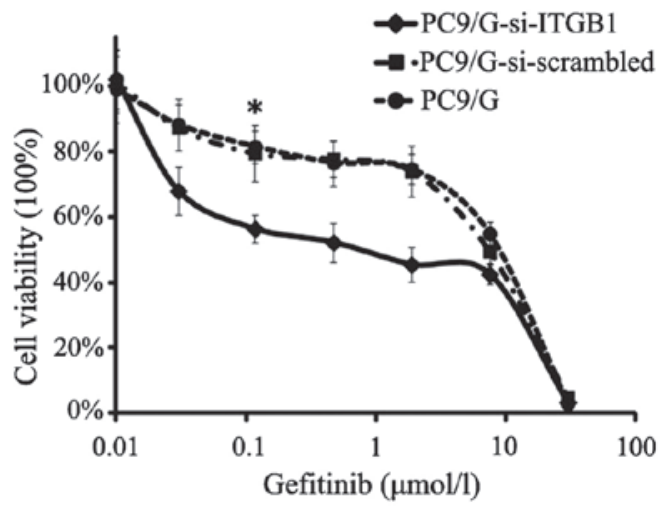

D

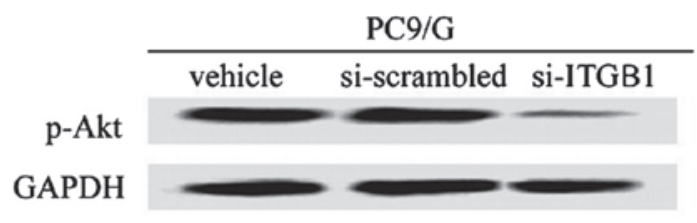

Figure 2. Characterization of integrin $\beta 1$-knockdown and analysis of the downstream pathway of EGFR signaling in PC9/G cells. (A) Western blot analysis of integrin expression in PC9/G cells transfected with three types of vector. Following transient RNA interference, integrin $\beta 1$ expression was almost inhibited in PC9/G cells. (B) Growth-inhibitory effect of Gef on integrin $\beta 1$-knockdown PC9/G cells determined by 3-(4,5-dimethylthiazol-2-yl)-2,5-diphenyltetrazolium bromide assay. Following transfection with vectors, PC9/G cells were exposed to the indicated concentrations of Gef for $72 \mathrm{~h}$. "P<0.05 vs. PC9/G and PC9/G-si scrambled cells. (C) Western blot analysis of PI3K/Akt and mitogen-activated protein kinase pathway of EGFR signaling in PC9 and PC9/G cells. Cells were placed in medium containing $0,0.02,0.2$ and $2 \mu \mathrm{M}$ Gef for $6 \mathrm{~h}$ and harvested in buffer. Samples $(20 \mu \mathrm{g})$ were separated by sodium dodecyl sulfate polyacrylamide gel electrophoresis, transferred to a membrane and blotted with anti-p-Akt and anti-p-Erk antibodies. (D) Western blot analysis of activation of PI3K/Akt in integrin-knockdown PC9/G cells. Following transfection with vectors, PC9/G cells were harvested in buffer. Total cellular lysates (20 $\mu \mathrm{g})$ were separated on gel, transferred to membranes and blotted. Knockdown of integrin $\beta 1$ induced a significant decrease in p-Akt expression. EGFR, epidermal growth factor receptor; Gef, gefinitib; PI3K, phosphoinositide 3-kinase; ITGB1, p, phosphorylated; integrin $\beta 1$; si, short interfering; Akt, protein kinase B; ERK/Erk, extracellular signal-regulated kinase.

and medium containing $2 \%$ fetal bovine serum (Gibco; Thermo Fisher Scientific, Inc.) was added to induce transgene expression. Following transfection for 24 h, 48 h, 72 h, 4 and 5 days, respectively, the number of cells exhibiting green GFP fluorescence and the total number of cells was counted using a fluorescence microscope (Olympus Corporation, Tokyo, Japan). Transfection efficiency (\%) was calculated using the following formula: (number of positive cells/number of total cells) x 100 .

Gene status and gene expression analysis. In order to evaluate EGFR sequence variations, polymerase chain reaction (PCR) amplifications of genomic DNA isolated from NSCLC cell lines were conducted using nested primers to amplify EGFR exons 18-21. Briefly, total DNA was extracted from cells using DNA extraction kits [Tiangen Biotech (Beijing) Co., Ltd., Beijing, China]. The following primers were used: Forward, 5'-CAAATGAGCTGGCAAGTGCCGTGTC-3' and reverse, 5'-GAGTTTCCCAAACACTCAGTGAAAC-3' for external exon 18; Forward, 5'-CAAGTGCCGTGTCCTGGCACCCAA GC-3' and reverse, 5'-CCAAACACTCAGTGAAACAA AGAG-3' for internal exon 18; forward, 5'-GCAATATCAGC CTTAGGTGCGGCTC-3' and reverse, 5'-CATAGAAAGTG AACATTTAGGATGTG-3' for external exon 19; forward, 5'-CCTTAGGTGCGGCTCCACAGC-3' and reverse, 5'-CAT
TTAGGATGTGGAGATGAGC-3' for internal exon 19; forward, 5'-CCATGAGTACGTATTTTGAAACTC-3' and reverse, 5'-CATATCCCCATGGCAAACTCTTGC-3' for external exon 20; forward, 5'-GAAACTCAAGATCGCATTCATGC-3' reverse, 5'-GCAAACTCTTGCTATCCCAGGAG-3' for internl exon 20; forward, 5'-CTAACGTTCGCCAGCCATAAGTCC-3' and reverse, 5'-GCTGCGAGCTCACCCAGAATGTCTGG-3' for external exon 21; forward, 5'-CAGCCATAAGTCCTCGAC GTGG-3' and reverse, 5'-CATCCTCCCCTGCATGTG TTAAAC-3' for internal exon 21. A total of 50 ng total DNA was used as a template for each reaction. PCR was performed under the following conditions: Pre-incubation at $95^{\circ} \mathrm{C}$ for $15 \mathrm{~min}$, followed by amplification for 35 cycles $\left(95^{\circ} \mathrm{C}\right.$ for $20 \mathrm{sec}$, $60^{\circ} \mathrm{C}$ for $30 \mathrm{sec}, 72^{\circ} \mathrm{C}$ for $1 \mathrm{~min}$ ) with a final extension step at $72^{\circ} \mathrm{C}$ for $10 \mathrm{~min}$. Subsequently, the products were directly sequenced by Invitrogen (Thermo Fisher Scientific, Inc.). Basal gene expression analysis of NSCLC cell lines was performed on RNA extracted from subconfluent cell cultures, using the BiostarH-140s microarray platform (China United Gene Health Industry Ltd., Hong Kong, China). Briefly, total RNA was extracted using the Trizol Plus Kit (Takara Bio, Inc., Shiga, Japan). A fluorescent labeling cDNA probe was generated from $3 \mu \mathrm{g}$ RNA using reverse transcriptase, Cy3-dCTP and Cy5-dCTP (all purchased from Shanghai BioStar Genechip Inc., Shanghai, China). Labeled cDNA was then hybridized using the 
Table III. Effect of gefitinib with or without LY294002 on cell proliferation, apoptosis and cell cycle progression of PC9/G-si-scrambled/ITGB1 cells.

A, Gefitinib alone

\begin{tabular}{|c|c|c|c|c|}
\hline \multirow[b]{2}{*}{ Cell } & \multirow[b]{2}{*}{$\mathrm{IC}_{50}$ values, $\mu \mathrm{M}$} & \multirow[b]{2}{*}{ Apoptotic rate, $\%$} & \multicolumn{2}{|c|}{ Cell cycle phase, $\%$} \\
\hline & & & $\mathrm{G} 0 / \mathrm{G} 1$ & $\mathrm{~S}$ \\
\hline PC9/G-si-scrambled & $6.85 \pm 0.25$ & $6.6 \pm 0.51$ & $58.8 \pm 4.6$ & $14.9 \pm 1.9$ \\
\hline PC9/G-si-ITGB1 & $0.09 \pm 0.006^{\mathrm{b}}$ & $24.0 \pm 3.12^{\mathrm{b}}$ & $75.3 \pm 3.5^{\mathrm{b}}$ & $5.1 \pm 2.7^{b}$ \\
\hline
\end{tabular}

B, Gefitinib+LY294002

\begin{tabular}{|c|c|c|c|c|}
\hline \multirow[b]{2}{*}{ Cell } & \multirow[b]{2}{*}{$\mathrm{IC}_{50}$ values, $\mu \mathrm{M}$} & \multirow[b]{2}{*}{ Apoptotic rate, $\%$} & \multicolumn{2}{|c|}{ Cell cycle phase, $\%$} \\
\hline & & & G0/G1 & $\mathrm{S}$ \\
\hline PC9/G-si-scrambled & $0.098 \pm 0.009^{\mathrm{a}}$ & $22.4 \pm 1.10^{\mathrm{a}}$ & $75.4 \pm 3.4^{\mathrm{a}}$ & $9.2 \pm 2.2^{\mathrm{a}}$ \\
\hline PC9/G-si-ITGB1 & $0.087 \pm 0.004$ & $26.0 \pm 0.91$ & $78.8 \pm 4.8$ & $4.8 \pm 1.2$ \\
\hline
\end{tabular}

BiostarH-140s cDNA microarray (Shanghai Biostar Genechip Inc.) at $42^{\circ} \mathrm{C}$. The array was imaged using the ScanArray 4000 scanner (GSI Group, Inc., Bedford, MA, USA) and images were processed by ImaGene 3.0 (GSI Group, Inc.).

Cell proliferation assay. The inhibition of cell proliferation was evaluated using the tetrazolium dye [3-(4,5-dimethylthiazol-2-yl) 2,5-diphenyltetrazolium bromide (MTT); Sigma-Aldrich] assay. Cells were seeded into 96-well plates at a density of 10,000 cells/well. Twenty-four hours following seeding, cells were exposed to various concentrations of gefitinib $(0,0.001,0.005,0.01,0.05,5.0,10.0,20.0$ and $40.0 \mu \mathrm{mol} / \mathrm{l})$ with or without LY294002 $(25 \mu \mathrm{mol} / 1)$. Seventy-two hours following drug treatment, cells were incubated with MTT $(5 \mathrm{mg} / \mathrm{ml})$ for $4 \mathrm{~h}$ at $37^{\circ} \mathrm{C}$. Culture medium containing MTT was subsequently removed and formazan crystals were dissolved in $200 \mu \mathrm{l}$ dimethyl sulfoxide (Shanghai Pharmaceuticals Holding Co., Ltd., Shanghai, China). Cell proliferation inhibition was determined by measuring the absorbance at $530 \mathrm{~nm}$ using a Multiskan MK3 microplate reader (Thermo Labsystems, Helsinki, Finland). These experiments were performed in quadruplicate on three separate occasions.

Cell cycle analysis. Cells $\left(4 \times 10^{5}\right.$ cells $\left./ \mathrm{ml}\right)$ in the logarithmic growth phase were seeded into six-well plates. The two cell lines (PC9 and PC9/G cells) were incubated for $24 \mathrm{~h}$ in serum free medium (Gibco; Thermo Fisher Scientific, Inc.) to arrest the cell cycle in the $G_{0}$ phase. The cells were then incubated in DMEM (Gibco; Thermo Fisher Scientific, Inc.) supplemented with $10 \%$ fetal bovine serum (Gibco; Thermo Fisher Scientific, Inc.). After $\sim 48 \mathrm{~h}$ incubation, the cell lines were treated with $0.03 \mu \mathrm{mol} / 1$ gefitinib, respectively. Cells were harvested by trypsinization, fixed in $70 \%$ ice-cold ethanol for $2 \mathrm{~h}$ and stained with propidium iodide (Beijing Biosea Biotechnology
Co. Ltd., Beijing, China). Cell cycle analysis was performed using a FC500 flow cytometer (Beckman Coulter, Inc., Brea, CA, USA).

$P C R$. Integrin $\beta 1$ RNA was amplified from the complementary DNA of PC9 and PC9/G by the SYBR Green real-time PCR kit (Toyobo Co., Ltd., Osaka, Japan). Integrin $\beta 1$ forward, CAAAGGAACAGCAGAGAAGC and reverse, ATTGAGTAAGACAGGTCCATAAGG. GAPDH forward, TGGTATCGTGGAAGGACTCATGAC and reverse, ATGCCAGTGAGCTTCCCGTTCAGC. Following $3 \mathrm{~min}$ of pre-incubation at $95^{\circ} \mathrm{C}, \mathrm{PCR}$ amplification was performed for 40 cycles $\left(94^{\circ} \mathrm{C}\right.$ for $5 \mathrm{sec}, 61^{\circ} \mathrm{C}$ for $\left.34 \mathrm{sec}\right)$, followed by a final melting curve step (from 60 to $95^{\circ} \mathrm{C} ; 1^{\circ} \mathrm{C} / \mathrm{min}$ ). The $2^{-\Delta \Delta \mathrm{Cq}}$ method was used to analyze the relative quantitative expression levels of integrin $\beta 1$, while GAPDH functioned as an internal control gene.

Western blot analysis. Cells were lysed in radioimmunoprecipitation assay buffer (Beyotime Institute of Biotechnology, Shanghai, China). The Bradford assay (22) was used to determine total protein concentrations, which were normalized to $1 \mu \mathrm{g} / \mu \mathrm{l}$ for all samples. Subsequently, samples were prepared in loading buffer (Beyotime Institute of Biotechnology) and heated to $95^{\circ} \mathrm{C}$ for $10 \mathrm{~min}$. The samples were separated on $8 \%$ polyacrylamide gels for total EGFR, phospho-EGFR and integrin $\beta 1$, and $10 \%$ gels for total Akt, phospho-Akt, c-MET, Erk and phospho-Erk. Briefly, protein lysates $(20 \mu \mathrm{l})$ in loading buffer from each cell line were loaded into each well. Wet transfer was performed for $2.5 \mathrm{~h}$ at constant current (200 mA) using nitrocellulose membranes (EMD Millipore, Billerica, MA, USA). The membrane was subsequently blocked for $1 \mathrm{~h}$ in $5 \%$ non-fat milk in $0.2 \%$ Tris-buffered saline Tween 20 (TBST; Beyotime Institute of Biotechnology). The membrane was then 
washed three times in $0.2 \%$ TBST for 10 min each and incubated overnight at $4^{\circ} \mathrm{C}$ with primary antibodies against total EGFR, phospho-EGFR, integrin $\beta 1$, total Akt, phospho-Akt, c-MET, Erk or phospho-Erk, respectively. Subsequently, the membrane was washed three times in $0.2 \%$ TBST for $10 \mathrm{~min}$ each. Horseradish peroxidase-conjugated goat anti-rabbit (cat. no. sc-2004) or anti-mouse (cat. no. sc-2055) immunoglobulin G (Santa Cruz Biotechnology, Inc., Santa Cruz, CA, USA) were used as secondary antibodies for enhanced chemiluminescence (Cell Signaling Technology, Inc.).

Apoptosis assay. Spontaneous apoptosis, as well as apoptosis of cells in response to selective pharmacological inhibitors, gefitinib (selective EGFR TKI) and LY294002 (selective PI3K inhibitor), were examined using Annexin V-PE-Cy5/PI staining (Biosea Biotechnology Company, China) on a FC500 flow cytometer (Beckman Coulter, Inc., CA, USA).

Statistical analysis. Data are presented as the mean \pm standard deviation. One way analysis of variance was used to assess the observed differences of samples more than two groups. For two groups of samples, the Student's t-test was used to assess statistical significance. All statistical tests were two-sided and $\mathrm{P}<0.05$ was considered to indicate a statistically significant difference.

\section{Results}

Generation of cell line with acquired resistance to gefitinib. The PC9/G gefitinib-resistant cell line was established by exposing PC9 cells to MNNG and gefitinib. The PC9 and PC9/G cell lines demonstrated significant differences in gefitinib sensitivity, as indicated by the evaluation of growth inhibition (Fig. 1A) and apoptosis in vitro. The $\mathrm{IC}_{50}$ of PC9 cells to gefitinib was $0.06 \pm 0.008 \mu \mathrm{mol} / 1$, while the $\mathrm{IC}_{50}$ of PC9/G cells was $7.29 \pm 0.39 \mu \mathrm{mol} / 1$ (Table I). In addition, the resistance index ( $\mathrm{IC}_{50}$ of resistant cells $/ \mathrm{IC}_{50}$ of parent cells) of PC9/G cells was 138 - to 256-fold greater than that of PC9 cells (data not shown). Following treatment of PC9 and PC9/G cells with gefitinib at a concentration of $0.1 \mu \mathrm{mol} / 1$ for $72 \mathrm{~h}$, the apoptotic rate of PC9 cells was $26.2 \pm 4.55 \%$ and that of PC9/G cells was $6.7 \pm 0.36 \%(\mathrm{P}<0.05$; Table I).

EGFR gene mutations and levels of phospho-EGFR are similar in the $P C 9$ and $P C 9 / G$ cell lines. DNA sequence analysis revealed that the gene status of EGFR in PC9 and $\mathrm{PC} 9 / \mathrm{G}$ cells was identical; the two cell lines demonstrated depletion of exon 19 and no exon 20 mutations (T790M). Whether there were any differences in gefitinib-induced inhibition of EGFR TK was investigated by examining the levels of phospho-EGFR. It was demonstrated that gefitinib was able to efficiently induce a similar decrease in phospho-EGFR levels in the PC9 and PC9/G cell lines (Fig. 1B). The gefitinib-resistant property of the $\mathrm{PC} / \mathrm{G}$ cell line is therefore not attributable to EGFR mutations or lack of efficacy of gefitinib on EGFR TK.

Gefitinib inhibits the cell cycle of PC9 but not PC9/G cells. Cell cycle analysis of the two cell lines was performed to exclude the possibility of differing cell proliferation rates between the two cell lines, which may result in the observed differences in gefitinib sensitivity. When cultured in $10 \%$ fetal calf serum-DMEM, the doubling time of PC9/G cells was $20.5 \mathrm{~h}$, which was similar to that of PC9 cells (19.7 h, P>0.05). There were also no significant differences in the number of cells at G0/G1 phase and S phase between the PC9/G and PC9 cell lines in rest state. However, following administration of $0.03 \mu \mathrm{mol} / 1$ gefitinib, PC9 cells were significantly inhibited at $\mathrm{G} 1$ phase $(\mathrm{P}<0.05)$, whereas no notable inhibition of the PC9/G cell cycle was observed (Table II).

Integrin $\beta 1$ is highly expressed in PC9/G cells and its knockdown restores gefitinib sensitivity. Western blot and PCR analyses revealed that there were significantly higher expression levels of integrin $\beta 1$ in $\mathrm{PC} 9 / \mathrm{G}$ cells, compared with those of PC9 cells (Fig. 1C and D). In order to determine whether this abnormally high expression of integrin was associated with the gefitinib resistance of PC9/G cells, a gene knockdown assay was conducted by shRNA interference. The efficiency of shRNA interference was confirmed by western blotting (Fig. 2A). It was demonstrated that knockdown of integrin in $\mathrm{PC} 9 / \mathrm{G}$ cells markedly increased the their sensitivity to gefitinib treatment, compared with those transfected with si-scrambled, exhibiting $\mathrm{IC}_{50}$ values of $6.85 \pm 0.25 \mu \mathrm{mol} / 1$ and $0.09 \pm 0.006 \mu \mathrm{mol} / 1$, respectively $(\mathrm{P}<0.05$; Fig. $2 \mathrm{~B})$. Furthermore, integrin knockdown did not affect the spontaneous apoptotic rate of PC9/G cells. Following gefitinib treatment, the apoptotic rate of PC9/G-si-ITGB1 cells significantly increased and a greater number of cells were arrested at G0/G1 phase than in PC9/G or PC9/G-si-scrambled cells (Table III). The observation that integrin $\beta 1$ shRNA restored the sensitivity of $\mathrm{PC} 9 / \mathrm{G}$ cells to gefitinib suggested that integrin $\beta 1$ may mediate the acquired gefitinib resistance of PC9/G cells.

Continuous activation of PI3K/Akt in the gefitinib-resistant $P C 9 / G$ cell line. The protein expression of c-MET, the amplification of which is associated with gefitinib resistance, was evaluated. No significant differences in c-MET protein expression were found between PC9 and PC9/G cells (Fig. 1C). The potential intracellular signaling pathways mediating gefitinib resistance in $\mathrm{PC} / \mathrm{G}$ cells were therefore further analyzed. A significant increase in the expression of phospho-Akt was detected in PC9/G cells, compared with that of PC9 cells, while the levels of phospho-Erk were similar between the two cell lines (Fig. 2C). Furthermore, gefitinib treatment was able to dose-dependently induce an inhibition of Akt phosphorylation in PC9 cells, but not in PC9/G cells (Fig. 2C).

To explore the underlying mechanism of continuous activation of PI3K/Akt in PC9/G cells following gefitinib treatment, the expression profiles of certain associated modulators were analyzed in the two cell lines. DNA microarray analysis demonstrated that only expression levels of integrin $\beta 1$ were found to be significantly different in the PC9/G cells compared with those of the PC9 cells. It was therefore hypothesized that the elevated expression of integrin $\beta 1$ observed in $\mathrm{PC} / \mathrm{G}$ cells may account for the resistance to EGFR inhibition.

Integrin $\beta 1$-mediated gefitinib resistance is dependent on the PI3K/Akt pathway. To explore whether enhanced PI3K 
signaling was responsible for integrin $\beta 1$-mediated resistance to gefitinib, the correlation between continuous activation of PI3K and increased expression of integrin $\beta 1$ was confirmed. It was demonstrated that knockdown of integrin $\beta 1$ expression significantly reduced Akt phosphorylation (Fig. 2D), suggesting that the high expression levels of integrin $\beta 1$ may be attributable to the sustained activity of the PI3K/Akt pathway in PC9/G cells. PC9/G cells were subsequently treated with gefitinib alone or in combination with the PI3K inhibitor LY294002. It was demonstrated that the sensitivity of PC $9 / \mathrm{G}$ to gefitinib, apoptosis levels and proportion of cells in G0/G1 phase were significantly increased in the gefitinib+LY294002 group, suggesting that the restoration of gefinitib sensitivity PC9/G cells may be PI3K/Akt pathway-dependent (Table I). Knockdown of integrin $\beta 1$ expression in $\mathrm{PC} 9 / \mathrm{G}$ cells exerted a similar restorative effect as that of LY294002 (Fig. 2B and D). Thus, inhibition of PI3K mimicked the sensitivity restoration effect of integrin $\beta 1$ knockdown in PC9/G cells. Taken together, the results of the present study indicate that an integrin-mediated overactivation of the PI3K/Akt pathway may underlie the mechanism of gefitinib resistance in $\mathrm{PC} 9 / \mathrm{G}$ cells.

\section{Discussion}

EGFR-targeted treatment in tumor therapy shows enhanced clinical efficacy and a reduction in adverse effects, compared with that of traditional chemotherapy $(23,24)$. Gefitinib and erlotinib, two small molecular anilinoquinazoline inhibitors of EGFR, have been approved for use in NSCLC therapy (25-27). However, the majority of patients who respond to EGFR TKI therapy will eventually relapse, and the median time to progression is only 6-12 months (5). The underlying mechanism of this acquired resistance to EGFR TKIs remains to be fully elucidated.

Integrins are heterodimeric cell surface glycoproteins, comprised of $\alpha$ and $\beta$ subunits, which bind ECM proteins and attach to the actin cytoskeleton within the cell (13). In addition to their structural function, integrins also have a crucial role in the mediation of signal transduction events, which require direct signaling via integrin-mediated activation of intracellular signaling cascades or modulation of growth factor-induced signaling (28). Recently, increasing evidence has indicated that integrin signaling may function in various aspects of tumor cell biology. Previous studies have indicated that integrin signaling blocks drug-induced apoptosis in myeloma, ovarian cancer and SCLC cells $(16,18,19)$. In the present study, the hypothesis that integrin may be involved in mediating gefitinib resistance of NSCLC cells was evaluated. The PC9/G NSCLC cell line model, with acquired resistance to gefitinib, was initially established. It was subsequently demonstrated that integrin $\beta 1$ signaling inhibited gefitinib-induced apoptosis. It was also found that integrin was abnormally highly expressed in $\mathrm{PC} 9 / \mathrm{G}$ cells, and that knockdown of integrin was able to effectively restore the sensitivity of PC9/G cells to gefitinib. These results indicated that integrin signaling also contributed to the development of resistance to EGFR-targeted agents, in addition to previously reported chemotherapeutic drugs, such as paclitaxel and carboplatin $(18,29)$.
Direct signaling via integrin-mediated activation is mediated by the activation of intracellular signaling pathways through binding to tyrosine phosphorylated focal adhesion kinase (FAK) (30). The most essential downstream pathways activated by integrin-ECM binding are the PI3K/Akt and mitogen activated protein kinase pathways, which have critical roles in tumorigenesis and therapeutic resistance (31). Transformed cells, including the majority of lung cancer cell lines, always develop the ability to survive and proliferate in the absence of cell adhesion (12). Recently, it was reported that activation of Akt was able to be induced by integrin $\beta 1$, in a manner independent of FAK and EGFR activity $(20,32)$. In the present study, it was demonstrated that there was a continuous activation of PI3K/Akt in the gefitinib-resistant PC9/G cell line and that depletion of integrin $\beta 1$ by RNAi inhibited this activation. It was also revealed that integrin $\beta 1$-mediated resistance to gefitinib was dependent on the PI3K signaling pathway.

Akt-mediated phosphorylation negatively regulates numerous pro-apoptotic factors, including Bad, caspase 9 and the forkhead transcription factors, and positively regulates survival factor nuclear factor $(\mathrm{NF})-\kappa \mathrm{B}$; therefore, any of these downstream molecules may be involved in conferring integrin $\beta 1$-mediated drug resistance (33). In the present study, DNA microarry analysis identified increased expression levels of $\mathrm{NF}-\kappa \mathrm{B}$ in $\mathrm{PC} 9 / \mathrm{G}$ cells (data not shown). It is possible that the activation of $\mathrm{NF}-\kappa \mathrm{B}$ confers a survival advantage to $\mathrm{PC} 9 / \mathrm{G}$ cells treated with gefitinib. In addition, previous studies have shown that Akt may prevent the release of cytochrome $c$ from mitochondria, thus contributing to tumor cell survival and inhibiting apoptosis $(11,29,34)$. Whether this is the case for gefitinib resistance in PC9/G cell lines remains to be elucidated.

In addition to direct signaling, integrin-mediated signal transduction may function via joint integrin/TK receptor signaling (35). Numerous growth factor receptors have previously been demonstrated to interact with integrins to transduce stronger, more efficient signals to downstream molecules $(28,35)$. It is therefore plausible that the TK activity of EGFR may be activated via an interaction with integrin, bypassing the inhibitory effects of EGFR antibody. However, this mechanism of resistance to EGFR antibody is not possible for gefitinib, a small molecule EGFR TKI.

Following the generalized clinical application of EGFR-targeted therapy, increasing numbers of NSCLC patients may be found to have inherent or acquired resistance. To develop novel therapeutic strategies for these patients, a full understanding of the molecular events underlying the resistance to EGFR inhibitors is required. In the present study, integrin $\beta 1$-mediated activation of the PI3K/Akt pathway was identified as one mechanism of survival and acquired therapeutic resistance to EGFR TKIs in NSCLC cells. It was therefore hypothesized that co-targeting integrin $\beta 1$ and EGFR simultaneously may present a potential strategy to overcome NSCLC resistance mediated by integrin.

\section{Acknowledgements}

The present study was supported by the Natural Science Foundation of China (grant no. 30873023). 


\section{References}

1. Torre LA, Bray F, Siegel RL, Ferlay J, Lortet-Tieulent J and Jemal A: Global cancer statistics, 2012. CA Cancer J Clin 65: 87-108, 2015.

2. Normanno N, Bianco C, De Luca A and Salomon DS: The role of EGF-related peptides in tumor growth. Front Biosci 6 : D685-D707, 2001.

3. Maemondo M, Inoue A, Kobayashi K, et al: Gefitinib or chemotherapy for non-small-cell lung cancer with mutated EGFR. N Engl J Med 362: 2380-2388, 2010

4. Rosell R, Carcereny E, Gervais R, et al; Spanish Lung Cancer Group in collaboration with Groupe Français de PneumoCancérologie and Associazione Italiana Oncologia Toracica: Erlotinib versus standard chemotherapy as first-line treatment for European patients with advanced EGFR mutation-positive non-small-cell lung cancer (EURTAC): A multicentre, open-label, randomised phase 3 trial. Lancet Oncol 13: 239-246, 2012.

5. Nguyen KS, Kobayashi S and Costa DB: Acquired resistance to epidermal growth factor receptor tyrosine kinase inhibitors in non-small-cell lung cancers dependent on the epidermal growth factor receptor pathway. Clin Lung Cancer 10: 281-289, 2009.

6. Pao W, Miller VA, Politi KA, Riely GJ, Somwar R, Zakowski MF, Kris MG and Varmus H: Acquired resistance of lung adenocarcinomas to gefitinib or erlotinib is associated with a second mutation in the EGFR kinase domain. PLoS Med 2: e73, 2005.

7. Thomson S, Buck E, Petti F, Griffin G, Brown E, Ramnarine N, Iwata KK, Gibson N and Haley JD: Epithelial to mesenchymal transition is a determinant of sensitivity of non-small-cell lung carcinoma cell lines and xenografts to epidermal growth factor receptor inhibition. Cancer Res 65: 9455-9462, 2005.

8. Suda K, Tomizawa K, Fujii M, Murakami H, Osada H, Maehara Y, Yatabe Y, Sekido Y and Mitsudomi T: Epithelial to mesenchymal transition in an epidermal growth factor receptor-mutant lung cancer cell line with acquired resistance to erlotinib. J Thorac Oncol 6: 1152-1161, 2011.

9. Onitsuka T, Uramoto H, Nose N, Takenoyama M, Hanagiri T, Sugio K and Yasumoto K: Acquired resistance to gefitinib: The contribution of mechanisms other than the T790M, MET, and HGF status. Lung Cancer 68: 198-203, 2010.

10. Shintani Y, Maeda M, Chaika N, Johnson KR and Wheelock MJ: Collagen I promotes epithelial-to-mesenchymal transition in lung cancer cells via transforming growth factor-beta signaling. Am J Respir Cell Mol Biol 38: 95-104, 2008.

11. Damiano JS, Cress AE, Hazlehurst LA, Shtil AA and Dalton WS Cell adhesion mediated drug resistance (CAM-DR): Role of integrins and resistance to apoptosis in human myeloma cell lines. Blood 93: 1658-1667, 1999.

12. Giancotti FG and Ruoslahti E: Integrin signaling. Science 285 $1028-1032,1999$

13. Hynes RO: Integrins: Bidirectional, allosteric signaling machines. Cell 110: 673-687, 2002

14. White DE, Kurpios NA, Zuo D, Hassell JA, Blaess S, Mueller U and Muller WJ: Targeted-integrin in a transgenic mouse mode disruption of human breast cancer reveals an essential role in mammary tumor induction. Cancer Cell 6: 159-170, 2004

15. Zutter MM, Santoro SA, Staatz WD and Tsung YL: Re-expression of the alpha 2 beta 1 integrin abrogates the malignant phenotype of breast carcinoma cells. Proc Natl Acad Sci USA 92: 7411-7415, 1995.

16. Emmons MF, Gebhard AW, Nair RR, Baz R, McLaughlin ML, Cress AE and Hazlehurst LA: Acquisition of resistance toward HYD1 correlates with a reduction in cleaved $\alpha 4$ integrin expression and a compromised CAM-DR phenotype. Mol Cancer Ther 10: 2257-2266, 2011

17. Martin S, Janouskova $\mathrm{H}$ and Dontenwill M: Integrins and $\mathrm{p} 53$ pathways in glioblastoma resistance to temozolomide. Front Oncol 2: 157, 2012.

18. Scalici JM,Harrer C, Allen A, Jazaeri A, Atkins KA, McLachlan KR and Slack-Davis JK: Inhibition of $\alpha 4 \beta 1$ integrin increases ovarian cancer response to carboplatin. Gynecol Oncol 132: 455-461, 2014

19. Hodkinson PS, Mackinnon AC and Sethi T: Extracellular matrix regulation of drug resistance in small-cell lung cancer. Int J Radiat Biol 83: 733-741, 2007.
20. Velling T, Stefansson A and Johansson S: EGFR and beta1 integrins utilize different signaling pathways to activate Akt. Exp Cell Res 314: 309-316, 2008.

21. Koizumi F, Shimoyama T, Taguchi F, Saijo N and Nishio K: Establishment of a human non-small cell lung cancer cell lines resistant to gefitinib. Int J Cancer 116: 36-44, 2005.

22. Bradford MM: A rapid and sensitive method for the quantitation of microgram quantities of protein utilizing the principle of protein-dye binding. Anal Biochem 72: 248-254, 1976.

23. Laskin JJ and Sandler AB: Epidermal growth factor receptor: A promising target in solid tumors. Cancer Treat Rev 30: 1-17, 2004.

24. Zhou C, Wu YL, Chen G, Feng J, Liu XQ, Wang C, Zhang S, Wang J, Zhou S, Ren S,et al: Erlotinib versus chemotherapy as first-line treatment for patients with advanced EGFR mutation-positive non-small-cell lung cancer (OPTIMAL, CTONG-0802): A multicentre, open-label, randomised, phase 3 study. Lancet Oncol 12: 735-742, 2011.

25. Fukuoka M, Yano S, Giaccone G, Tamura T, Nakagawa K, Douillard JY, Nishiwaki Y, Vansteenkiste J, Kudoh S, Rischin D, et al: Multi-institutional randomized phase II trial of gefitinib for previously treated patients with advanced nonsmall-cell lung cancer (The IDEAL 1 Trial) [corrected]. J Clin Oncol 21: 2237-2246, 2003.

26. Thatcher N, Chang A, Parikh P, Rodrigues Pereira J, Ciuleanu T, von Pawel J, Thongprasert S, Tan EH, Pemberton K, Archer V and Carroll K: Gefitinib plus best supportive care in previously treated patients with refractory advanced non-small-cell lung cancer: Results from a randomized, placebo-controlled, multicentre study (Iressa Survival Evaluation in Lung Cancer). Lancet 366: 1527-1537, 2005.

27. Shepherd FA, Rodrigues Pereira J, Ciuleanu T, Tan EH, Hirsh V, Thongprasert S, Campos D, Maoleekoonpiroj S, Smylie M, Martins R, et al; National Cancer Institute of Canada Clinical Trials Group: Erlotinib in previously treated non-small-cell lung cancer. N Engl J Med 353: 123-132, 2005.

28. Parise LV, Lee J and Juliano RL: New aspects of integrin signaling in cancer. Semin Cancer Biol 10: 407-414, 2000.

29. Aoudjit $F$ and Vuori K: Integrin signaling inhibits paclitaxel-induced apoptosis in breast cancer cells. Oncogene 20: 4995-5004, 2001.

30. Plopper GE, McNamee HP, Dike LE, Bojanowski K and Ingber DE: Convergence of integrin and growth factor receptor signaling pathways within the focal adhesion complex. Mol Biol Cell 6: 1349-1365, 1995.

31. Lee HY, Srinivas H, Xia D, Lu Y, Superty R, LaPushin R, Gomez-Manzano C, Gal AM, Walsh GL, Force T, et al: Evidence that phosphadidylinositol 3-kinase- and mitogen-activated protein kinase kinase-4/c-Jun NH2-terminal kinase-dependent pathways cooperate to maintain lung cancer cell survival. J Biol Chem 278: 23630-23638, 2003.

32. Zeller KS, Idevall-Hagren O, Stefansson A, Velling T, Jackson SP, Downward J, Tengholm A and Johansson S: PI3-kinase $\mathrm{p} 110 \alpha$ mediates $\beta 1$ integrin-induced Akt activation and membrane protrusion during cell attachment and initial spreading. Cell Signal 22: 1838-1848, 2010.

33. Gilmore AP, Metcalfe AD, Romer LH and Streuli CH: Integrin-mediated survival signals regulate the apoptotic function of bax through conformation and subcellular localization. J Cell Biol 149: 431-446, 2000

34. Sethi T, Rintoul RC, Moore SM, MacKinnon AC, Salter D, Choo C, Chilvers ER, Dransfield I, Donnelly SC, Strieter R and Haslett C: Extracellular matrix proteins protect small cell lung cancer cells against apoptosis: A mechanism for small cell lung cancer growth and drug resistance in vivo. Nat Med 5 $662-668,1999$.

35. Cabodi S, Morello V, Masi A, Cicchi R, Broggio C, Distefano P, Brunelli E, Silengo L, Pavone F, Arcangeli A, et al: Convergence of integrins and EGF receptor signaling via $\mathrm{PI} 3 \mathrm{~K} / \mathrm{Akt} / \mathrm{FoxO}$ pathway in early gene Egr-1 expression. J Cell Physiol 218: 294-303, 2009. 